\title{
Person-first language: What it means to be a "person"
}

$\mathrm{T}$

he graphic that appeared on Rachel Cohen-Rottenberg's Facebook page struck her as problematic in several ways. First, there was the text: "See the Person Not the Disability."

Why not see both the person and the disability? Is a disability something one should be ashamed of? Does it make you less human?

And then there was the matter of those shadows. The graphic depicts four stick figures - two men, two women - like those on the doors of public restrooms. They are all standing. Behind them, though, are shadows of figures in wheelchairs.

In other words, the image implies that being a "person" means being able-bodied, Cohen-Rottenberg, author of the book Blazing My Trail: Living and Thriving with Autism, suggested on her blog (www.journeyswithautism .com/2012/04/25/the-problem-with -person-first-language).

This is the paradox of the personfirst language movement. Advocates for using phrases such as "person with disabilities" rather than "disabled person" want the world to look past the wheelchairs and the guide dogs and the hearing aids. A person is not defined by a diagnosis, the adage goes.

But some disability rights supporters suggest that person-first language may actually be narrowing attitudes about "humanness." More effort should be put into incorporating disability into the concept of personhood, they claim, rather than on attempting to put distance between them.

"I have two basic issues with personfirst language. First, the insistence on putting the person before the disability betrays the assumption that disability somehow renders one less of a person. If that assumption were not present, there would be no reason to foreground the fact that we really are people, and that one has to put the disability aside in order to see that we're human," CohenRottenberg writes in an email.

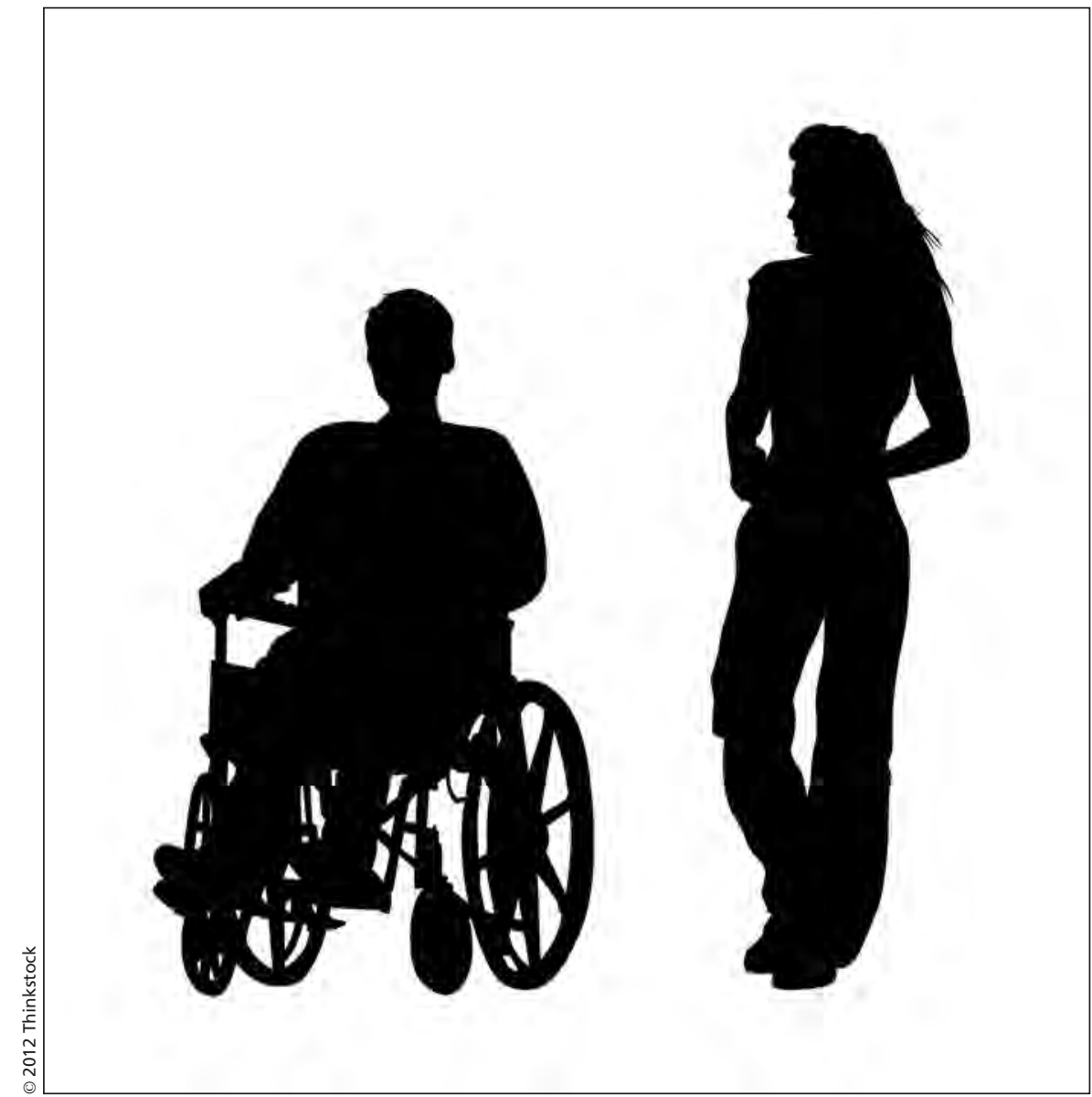

Does person-first language perpetuate the negative stereotype that someone with a disability is "less of a person" than someone without a disability?

"Second, by splitting off being the person from being disabled, the implication is that being a person means being able-bodied. After all, if I'm a 'person with disabilities,' and you don't look at the disabilities, then what am I without them?"

Though the intent behind person-first nomenclature is admirable, it has the potential to shape thinking in ways both unexpected and unintended, according to Tanya Titchkosky, who teaches in the Department of Humanities, Social Sciences and Social Justice Education at the University of Toronto in Ontario.

"It can control the way we think about what it means to be human. It reasserts that humanness is positive and reasserts that disability is negative," says
Titchkosky. "What is it about bringing the disability close to the human that will make their humanness disappear?"

Though person-first language certainly isn't responsible for the stigma that so often surrounds disease and disability, its growing popularity might be a symptom of society's failure to address a much bigger issue - how to improve the lives of people so often ignored in a world that doesn't always embrace physical or mental diversity. Another cause for concern is the zealousness of some language advocates to force everyone to conform to their rules.

"When it becomes a universally enforced, singular way of referring to disability, that is super dangerous," says Titchkosky. 
But for advocates of person-first language, it isn't about lexical domination or pushing disabilities aside and pretending they don't exist. It's about respect, dignity and shedding labels. It's about realizing people are so much more than their disabilities and to place disproportionate emphasis on this one characteristic does them a disservice.

"The point is to not categorize, to not judge. We need to focus on our similarities. Let's not focus on our differences," says Kathie Snow, a disability rights advocate who runs the "Disability is Natural" website (www.disabilityis natural.com). "A disability is a natural part of the human experience."

According to Snow, people with disabilities are not autistic, blind, deaf, learning disabled or any other label. They are fathers, sons, employers, employees, friends, neighbours, teachers, students and more. The point of person-first language, she suggests, is not to divorce "disability" from "person," but rather to think of disabilities like another human trait, such as gender or ethnicity. Unfortunately, says Snow, society just can't seem to see past the disability to the person.

"People with disabilities, in general, are deeply marginalized," she says. "They are not part of the social mainstream."

Snow believes person-first language can help move attitudes about disability in a new direction, and has dedicated a portion of her website to the topic (www.disabilityisnatural.com /explore/pfl). She first became aware of the insensitive labels often attached to individuals with disabilities 25 years ago, after her son was born prema- turely and soon after diagnosed with cerebral palsy.

"I never saw my son as quoteunquote handicapped," says Snow. "He's Benjamin. He's a person first." — Roger Collier, CMAJ

CMAJ 2012. DOI:10.1503/cmaj.109-4322

Editor's note: Second of a multi-part series.

Part I: Person-first language: Noble intent but to what effect? (www.cmaj.ca/lookup/doi/10.1503 /cmaj.109-4319).

Part III: Person-first language: Laudable cause, horrible prose (www.cmaj.ca/lookup/doi/10.1503 /cmaj.109-4338). 